\title{
Comparison of Safety, Efficacy and Outcomes of Robot Assisted Laparoscopic Pyeloplasty vs Conventional Laparoscopy
}

This article was published in the following Dove Press journal: Research and Reports in Urology

\section{Guglielmo Mantica \\ Francesca Ambrosini \\ Stefano Parodi (D) \\ Stefano Tappero \\ Carlo Terrone}

Department of Urology, Policlinico San Martino Hospital, University of Genova, Genova, Italy
Correspondence: Guglielmo Mantica Department of Urology, Policlinico San Martino Hospital, University of Genova, Largo Rosanna Benzi 10, Genova 16132, Italy

Tel +390105553935

Email guglielmo.mantica@gmail.com

\begin{abstract}
Pyeloplasty is considered the gold standard for the management of ureteropelvic junction obstruction in cases of flank pain, recurrent stone formation or infection, and deteriorating renal function. Over the last two decades, minimally invasive techniques such as robotic (RALP) and laparoscopic pyeloplasty (LP) have become increasingly popular and have been moderately replacing the open approach. This paper aims to provide a comprehensive up-to-date review on safety, efficacy and outcomes regarding robotic repair of UPJO compared to the conventional laparoscopic procedure. RALP represents a viable and innovative alternative to conventional LP with a comparable success and complication rate both in adult and in paediatric fields. The robotic approach seems to add further technical advantages when compared to conventional LP but sustains a higher costs. Currently, the choice to adopt one of the different minimally invasive approaches depends on the surgeon's preference or experience, and on institutional availability.
\end{abstract}

Keywords: robotic pyeloplasty, laparoscopic pyeloplasty, ureteropelvic junction obstruction, hydronephrosis, pyeloplasty

\section{Introduction}

Ureteropelvic junction obstruction (UPJO) is one of the most common causes of hydronephrosis resulting from both congenital and acquired conditions. ${ }^{1}$ Clinical symptoms may present at any time ranging from intrauterine life to late adulthood. Pyeloplasty still remains the gold standard for the management of UPJO in cases of flank pain, recurrent stone formation or infection, and deteriorating renal function. ${ }^{2}$

Historically, the open approach had long been regarded as the standard treatment. However, over the last 20 years, minimally invasive techniques have become increasingly popular thanks to several benefits such as smaller incisions, shorter length of stay and reduced pain. ${ }^{3}$

In 1993 Schuessler et al described the first laparoscopic pyeloplasty (LP) noting the perceived advantages and comparable results with reference to the open technique. ${ }^{4}$

However, compared to open pyeloplasty, LP involves more technical difficulties, a longer learning curve, increased operative time and advanced laparoscopic skills for precise tissue dissection and intracorporeal suturing. ${ }^{5}$

The introduction of robotic technology revolutionised the surgical field. The first Robot-assisted LP (RALP) series was reported by Gettman et al in $2002 .^{6}$ In recent years there has been considerable interest in RALP because it offers the advantages of conventional laparoscopy in terms of perioperative morbidity, but with a shorter 
learning curve and potentially improved outcomes thanks to a greater range of motion and a magnified three-dimensional vision. 5

This paper aims to provide a comprehensive up-to-date review on safety, efficacy, and outcomes of robotic repair of UPJO when compared to the conventional laparoscopic procedure.

\section{Materials and Methods}

A non-systematic literature search of PubMed and EMBASE databases was carried out in August 2020 to select relevant papers published between 2000 and 2020 which provided data on LP and RALP for the treatment of UPJO. The search string was ("pyeloplasty") AND ("robotic pyeloplasty") OR ('robot assisted laparoscopic pyeloplasty) OR ('robotic-assisted laparoscopic pyeloplasty) AND ("laparoscopic pyeloplasty"). The inclusion criteria were studies published in English language, studies reporting results for both adult and paediatric patients, studies providing original data and metanalyses, and studies describing clinical outcomes for LP and RALP. The exclusion criteria were editorials, case reports, commentaries, short communications and incomplete original data. Information about study type, sample size, technical procedure, peri- and post-operative outcomes, success rate and failure, complications and costs were analyzed.

\section{Operative Technique}

Patients eligible for pure laparoscopic and robot-assisted pyeloplasty are essentially the same. Similarly, RALP contraindications are similar to any laparoscopic procedure including active infection, severe cardiopulmonary disease, uncorrectable coagulopathy. ${ }^{7}$

\section{Conventional Laparoscopic Pyeloplasty}

Conventional LP requires grasping instruments, cutting and energy dissectors, needle drivers, aspirator, clips and a $10 \mathrm{~mm} 30^{\circ}$ or $0^{\circ}$ lens. The procedure is usually performed under general anaesthesia. ${ }^{4}$

Both the transperitoneal and the retroperitoneal approaches are described, although the latter remains technically challenging. ${ }^{8,9}$

As regards the transperitoneal route, the patient is positioned in a lateral flank position. A three $10 \mathrm{~mm}$ ports technique is usually performed. ${ }^{4}$ An additional $5 \mathrm{~mm}$ port could be used for liver retraction in rightsided procedures (Figure 1).

Furthermore, mini-laparoscopic pyeloplasty could be performed using a $5 \mathrm{~mm}$ camera-port $(2 \mathrm{~cm}$ lateral to the umbilicus) and two other $3 \mathrm{~mm}$-ports placed under direct vision along the midclavicular line. ${ }^{10}$

Moreover, some laparoendoscopic single site (LESS) pyeloplasty series' have been reported since $2007 .{ }^{11}$ LESS pyeloplasty is carried out through a single abdominal wall incision by placement of a single multi-instrument port.

Once the colon is mobilized medially, the proximal ureter can be identified just medial to the lower pole of the kidney. If necessary, the gonadal vein can be dissected. In selected cases, a transmesocolic approach for left side laparoscopic pyeloplasty is feasible. ${ }^{12}$ According to the

Figure I Conventional laparoscopic pyeloplasty trocars' placement. 


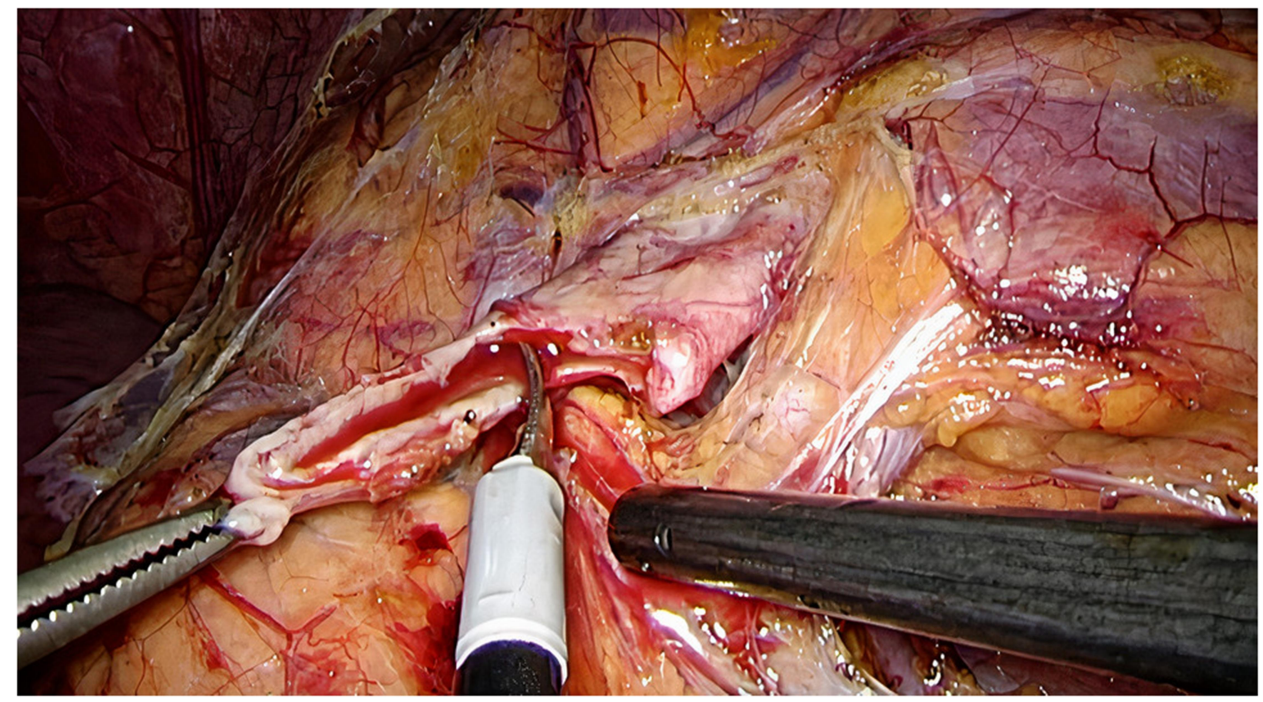

Figure 2 Anderson-Hynes dismembered procedure: the renal pelvis is circumferentially transacted above the UPJO.

Anderson-Hynes dismembered procedure, the renal pelvis is circumferentially transacted above the UPJO and the proximal ureter is usually spatulated on the lateral side with an interrupted suture (Figure 2).

Alternatively, different techniques of non-dismembered repairs have been described including Fenger pyeloplasty and Foley Y.V plasty. These methods do not require a complete disconnection of the pelvis and ureter and are recommended depending on the UPJO anatomy and the surgeon's preference. ${ }^{13,14}$

\section{Robotic-Assisted Laparoscopic Pyeloplasty}

Robotic technology has implemented the management of UPJO by providing magnified three-dimensional vision, tremor filtering, motion scaling, and extended range of motion resulting in easier dissection and suturing. Thanks to these advantages, RALP offers laparoscopic procedural benefits with a more rapid and efficient learning curve. ${ }^{5}$

Included in robotic instruments used are needle drivers, bipolar forceps, aspirator and monopolar scissors. Depending on the surgeon's preference, the camera consists of a $0^{\circ}$ or $30^{\circ}$ lens. Generally, the procedure is carried out under general anesthesia, although other anesthesiologic techniques for mini-invasive surgery such as spinal and epidural anesthesia are under investigation. ${ }^{15,16}$

The transperitoneal approach is usually favoured because of its more familiar anatomic landmarks and larger working area, although the retroperitoneal route is also feasible.
Patient positioning for transperitoneal laparoscopic and robotic pyeloplasty is essentially identical. Three trocars (two $8 \mathrm{~mm}$ robotic trocars and one $12 \mathrm{~mm}$ trocar $-d a$ Vinci ${ }^{\mathbb{R}} \mathrm{XI}$ ) are placed in a triangulated configuration: the two operative robotic ports are positioned respectively at the midpoint between the anterior superior iliac spine and the umbilicus, and, on the pararectal line, $1 \mathrm{~cm}$ beyond the costal arch. The 5-mm assistant port is positioned on the midline at the midpoint between the umbilicus and the xiphoid process. ${ }^{17}$ (Figure 3)

Recently, a short series of single-site robot-assisted pyeloplasty have been also reported where a single $25-\mathrm{mm}$ multichannel port containing an articulating robotic camera and two double-jointed robotic instruments was placed. ${ }^{18}$

Robotic technique for dismembered or nondismembered pyeloplasty follows the same steps as conventional LP. Initially, interrupted sutures for the pelviureteric anastomosis were described as reproductive of the LP procedure. Subsequently, most of the series' currently report a continuous running anterior and posterior suture for uretero-pelvic reconstruction. Further minimally invasive approaches that allow for minimal incisions of the retroperitoneum have recently been proposed. ${ }^{19,20}$ Presently, the literature does not provide any comparison studies regarding differing outcomes of interrupted or continuous suturing. ${ }^{21}$

\section{Stenting}

It is common practice to create a stented anastomosis both in LP and RALP. The retrograde versus anterograde way of stenting has been discussed over the years. ${ }^{22}$ 


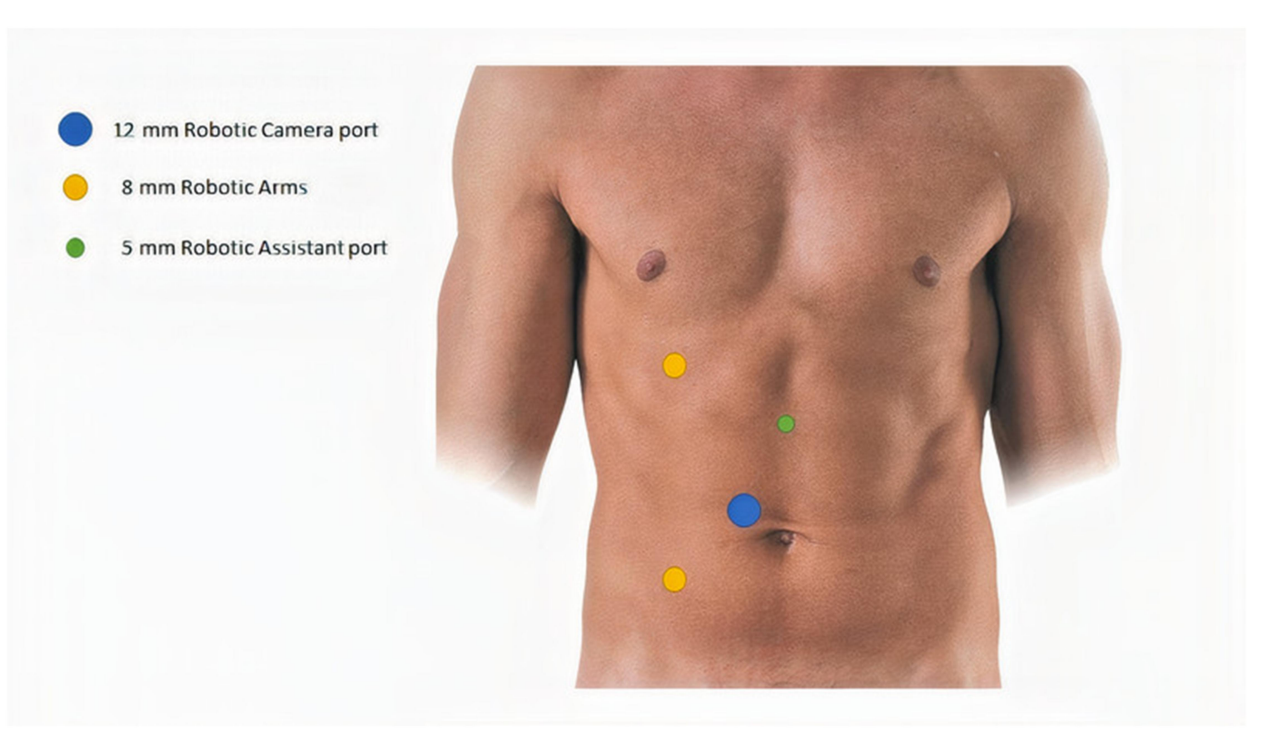

Figure 3 Robotic pyeloplasty trocars' placement.

Pyeloplasty usually follows cystoscopic retrograde stent positioning with the advantage of performing a preliminary retrograde pyelogram. On the other hand, initial stenting results in the collapse of the renal pelvis making identification of the UPJO point more difficult. In addition, a pre-placed stent may interfere with suturing. Antegrade stenting during pyeloplasty has been suggested to overcome these limits. ${ }^{23}$ However, antegrade stenting can sometimes be challenging, especially during the learning curve. In order to get the benefits of both antegrade and retrograde stenting, some authors have proposed the use of mono $\mathrm{J}$ stents which can easily be converted into a double-J stent such as the Contour. ${ }^{20}$ Similarly, other authors have recently proposed the use of a double-lumen ureteric stent. ${ }^{24}$ The double-lumen valve-controlled stent seems to support neo anastomoses healing and help in accurately monitoring both perioperative urine drainage and perianastomotic leakage.

Regardless of whether classic laparoscopic or robotassisted pyeloplasty is used, some authors have proposed stentless procedures, in both children and adults, with the same success rates as stented pyeloplasty. ${ }^{25}$

\section{Paediatric Setting}

With the current widespread use of minimally invasive techniques, LP can also be considered the gold standard treatment for UPJO in the paediatric population. Robotic pyeloplasty for UPJO management is the pioneer procedure of paediatric robotic surgery, although the real benefit of robotics remains controversial.
In fact, children have a unique anatomy and physiology when compared to adults, including more rapid gastric emptying times with increased small bowel distention, all of which making access more challenging. Moreover, the cranial position of the bladder and the laxity of the abdominal wall result in a higher risk of vascular or bowel injuries. ${ }^{26}$

The surgical steps are almost identical in both LP and RALP and are comparable to the procedures performed on adults. From a technical point of view, LP requires advanced laparoscopic skills, while robotic surgery allows the surgeon to overcome many technical challenges, in particular intracorporeal suturing. The limitations of robotic surgery continue to be the high cost and the size of robotic instruments. ${ }^{27}$

\section{Perioperative Outcomes}

A growing body of literature has examined perioperative outcomes of LP and RALP providing comparable results.

In 2018 Hong et $\mathrm{al}^{28}$ reported no need for conversion to open surgery among 216 patients treated with miniinvasive pyeloplasty (76 LP and 140 RALP) in a retrospective comparative study. A shorter operative time for RALP was observed when compared to LP in cases of simple pyeloplasty (122.29 \pm 32.64 vs $132.00 \pm$ 34.74 mins respectively, $p=0.042$ ) and in horseshoe kidney patients $(112.5 \pm 15$ vs $149.6 \pm 17.17$ mins; $p=$ 0.011 ), while no difference was recorded in cases of associated pyelolithotomy ( $p=0.656$ ).

In a systematic review conducted by Light et $\mathrm{al}^{29}$ RALP was found to have shorter operating times than 
LP (weighted mean difference [WMD] $26.71 \mathrm{~min}, 95 \% \mathrm{CI}$ 44.42-9.00; $\mathrm{P}=0.003$ ) and a shorter LOS (WMD 1.21 days, $95 \%$ CI 1.84-0.57; $\mathrm{P}=0.003$ ).

A more recent systematic review of 26 retrospective and prospective studies showed no statistically significant differences between RALP and LP with respect to operative time $(\mathrm{OR}=-12.12 ; 95 \% \mathrm{CI}-41.08-16.84 ; \mathrm{p}=$ $0.412)$, and length of stay (OR $=-0.87 ; 95 \% \mathrm{CI}-3.23-$ $1.49 ; \mathrm{p}=0.471){ }^{30}$

Regarding the best surgical access for both LP and RALP, the transperitoneal and the retroperitoneoscopic approaches have shown comparable outcomes in terms of operative time, morbidity, hospital stay, time to convalescence and success rate. The choice remains a matter of surgeon preference as the first offers a larger and more familiar working space while the second a direct approach to the UPJ and hilar vessels. ${ }^{31}$

Finally, Amòn Sesmero et al studied different pyeloplasty techniques and found no differences in success rates and complication rates between the Anderson-Hynes (A-H) plasty, the non-dismembered pyeloplasty and the Hellstro" $m$ technique (HT) $(\mathrm{p}>0.05)$. The mean surgical time for $\mathrm{A}-\mathrm{H}$ technique was longer than for the $\mathrm{Y}-\mathrm{V}$ Foley and Fenger plasty (202-44 minutes vs $147-27$ vs $124-30$, $\mathrm{p}<0.05){ }^{32}$

\section{Perioperative Paediatric Outcomes}

Regarding the perioperative outcomes in the paediatric population, in 2011 Sorensen et al found a complication rate of $2.2 \%$ and $3 \%$ after laparoscopic and robotic pyeloplasty, respectively. After adjusting for all the studies variables, subjects with preoperative comorbidities had 3.1 times higher odds for complication than patients without comorbidities $(p=0.001)$, while multivariate analysis indicated that a surgical approach had minimal effect on the rates of intraoperative and postoperative complications. ${ }^{33}$

More recently, two authors have evaluated the same outcomes confronting LP vs RALP. According to Andolfi et $\mathrm{al}^{34}$ results, success rates were comparable between the two minimally invasive approaches with average rates of $98.5 \%$ and $96.9 \%$ at a follow-up of 14.1 and 26.3 months for RALP and LP, respectively. RALP favoured lower complication rates as compared to LP, with a combined rate of $7.2 \%$ in the RALP group vs $14.3 \%$ in the LP group. Extracting data specific to infants, the average LOS was similar between RALP and LP. On the other hand, no significant difference was noted by Arksenov et $\mathrm{al}^{35}$ in the need to convert to open surgery in RAP vs LP $(1.46 \%$ vs $1.12 \%$ respectively, $\mathrm{p}=0.42$ ) nor in the complication rate $(4.23 \%$ vs $4.32 \%$ Clavien Dindo III-IV respectively, $\mathrm{p}=0.90)$.

\section{Operative Success}

Operative success was meant as patent ureteropelvic junction confirmed by radionuclide diuretic renogram or intravenous urography with a decrease in severity of hydronephrosis and an absence of symptoms. However, recently some authors have proposed Colour Doppler Ultrasonography as a non-invasive, fast, inexpensive and available modality for evaluating the success of pyeloplasty instead of the nuclear scan. ${ }^{36}$

Through time, LP and RALP have shown success rates comparable to those reported in older OP series', surpassing $95 \%$, while minimising the morbidity and ameliorating wound cosmesis. ${ }^{37,38}$

In 2014, Autorino et $\mathrm{al}^{5}$ observed no differences in terms of success and complication rates between LP and RLP. However, they concluded their systematic review stating that robotic pyeloplasty is likely to emerge as the new minimally invasive standard of care.

Hopf et al registered the long-term outcomes of patients treated with RLP, finding a success rate of $96.9 \%$ with an 8 -year failure-free survival of $91.5 \%$ overall and $96.3 \%$ when considering only stented pyeloplasties. Stentless RLP was associated with a significantly increased rate of postoperative urine leak compared to stented RLP. ${ }^{39}$

\section{Operative Success in Paediatric Population}

In a recent systematic review focused on the paediatric population, RALP $(\mathrm{n}=1233)$ was associated with a significantly higher success rate $(\mathrm{OR}=2.51 ; 95 \% \mathrm{CI}$ $1.08-5,83 ; \mathrm{p}=0.03)$ compared to LP $(\mathrm{n}=1021)$, whereas both procedures yielded overlapping results in terms of safety and reintervention rate. ${ }^{40}$

\section{Complications}

Complications include those often seen in other types of minimally invasive urologic procedures. Intraoperative complications encompass ligation of the lower pole artery, loss of a needle, hypercapnia, cutting of the ureteral stent, colonic injury and port site bleeding. Urine leak, hematoma formation, colonic lesion and stone formation are the main postoperative complications. ${ }^{38}$ 
RALP and LP yielded analogue results regarding overall mid and long-term complications (OR $=1 ; 95 \% \mathrm{CI}$ $1-1 ; \mathrm{p}=\mathrm{NA})$, urinary leakage $(\mathrm{OR}=0.57 ; 95 \% \mathrm{CI} 0.24$ $1.36 ; \mathrm{p}=0.206)$, transfusion rate $(\mathrm{OR}=0.44 ; 95 \% \mathrm{CI}$ $0.02-10.32 ; \mathrm{p}=0.613)$ and re-operation rate $(\mathrm{OR}=0.32$; $95 \%$ CI $0.01-8.24 ; \mathrm{p}=0.494){ }^{41}$

In 2006 Zhang retrospectively described a series of 56 transperitoneal LP, with intra-operative and post-operative complication rates respectively attested at $2.3 \%$ and $12.9 \%$, while the recurrent UPJO requiring secondary procedures ranged from $3.5 \%$ to $4.8 \%{ }^{42}$

In 2019 a comparison between 34 LP and 34 RALP at a single high-volume center found post-operative complication rates to respectively be noted at $8.8 \%$ and $5.9 \%$, with the prolonged urinary leakage the most common adverse event $(33.3 \%$ and $50 \%){ }^{43}$

According to the faculty review by Mendrek et al, no clear consensus exists about statistically significant differences between RALP and LP in terms of operative time and complication rates, while the two techniques are statistically equivalent regarding hospital readmissions and success rate. ${ }^{44}$

\section{Re-Do Pyeloplasty and Horseshoe Kidney}

The role of robotic and pure laparoscopic surgery on re-do pyeloplasty has not been investigated in detail. Zhang et $\mathrm{al}^{45}$ retrospectively evaluated patients who had undergone secondary RALP or LP for recurrent UPJO. They found that the mean operative time, suturing time, and hospitalization time of patients in the RALP group were significantly less than those in the LP group. However, the success rate of the RALP group and the LP group was found to be similar ( $87.7 \%$ and $85.7 \%$, respectively).

In recent years, robotic surgery in both adults and children has increasingly become the first choice even in cases of previous failed pyeloplasty. ${ }^{46}$

There are no comparative studies between RALP and LP regarding particular anatomical conditions such as horseshoe kidneys. However, there are numerous case reports and case series' in the literature that, in expert hands, show how both procedures are feasible and capable of guaranteeing good surgical success with limited complications. ${ }^{47,48}$

\section{Cost Analysis}

When evaluating different treatment approaches, costs have to be taken into account as well. Yu et $\mathrm{al}^{49}$ found RALP to be associated with a higher median cost $(\$ 11,829)$ than LP (\$ 8291). In the hands of surgeons experienced in LP, the transition to the robotic platform increased the cost by 2.7 times, as shown by Link et al. ${ }^{50}$ RALP offers the advantages of laparoscopy in terms of morbidity and, in addition, offers a quicker learning curve with the potential of improved results due to enhanced three-dimensional visualisation. For urologists who do not have extensive experience with intracorporeal suturing, the robotic approach can substantially increase the speed of learning and this reason alone may justify its high cost.

\section{Learning Curve and Surgeon's Perspective}

Rasool et al in 2019 recorded higher degrees of the surgeon fatigue index (SFI) for LP compared to RALP (7 v. 4.12, $\mathrm{p}<0.001$ ), which correlates with surgeon longevity. No differences were found in terms of post-operative pain control evaluated by the VAS score and mean hospital, while the operative time was significantly longer for LP $(187.76 \pm 22.1 \mathrm{~min}$ vs $136.76 \pm 25.1 \mathrm{~min}, \mathrm{p}<0.001)$, which is in disagreement with the previous cited review. ${ }^{43}$

The surgical learning curve has been evaluated in only a few studies for either laparoscopic or robotic pyeloplasty. Most of the authors found out that the learning curve of LP and RALP steadily decreased with collective surgical experience. ${ }^{51,52}$ Chammas MF et al ${ }^{53}$ evaluated 99 patients who had undergone 100 consecutive robotic procedures. Cases were divided into 4 groups of 25 consecutive procedures to analyse the learning curve. A significant decrease in hospital stay and surgical time was evident after 25 cases. More than about 40 RALP cases are needed to achieve mastery, a significant reduction in OT, length of stay, and postoperative pain. ${ }^{54,55}$

Bowen et al evaluated the role of proctoring and of an established robotic program and found that an experienced open surgeon and fellowship-trained surgeon can quickly attain levels of expertise with paediatric RALP. ${ }^{56}$

Laparoscopic surgery can be technically more challenging than robotics, but it also has the advantage of no docking and precise learning of how robots and consoles work.

Panek et $\mathrm{al}^{57}$ evaluated the learning curve for LP. They concluded that the surgical learning curve reflects the surgeon's experience with regard to the entire therapeutic process, and not exclusively their manual skills. Similarly, Zhu et $\mathrm{al}^{58}$ evaluated 50 consecutive laparoscopic pyeloplasties performed by two urologists from different urologic centres 
during their learning curve period in laparoscopy. They tried to assess any differences in the learning curve for two different laparoscopic approaches (retroperitoneal vs transperitoneal). They concluded that during the learning curve for laparoscopy young urologists should perform laparoscopic pyeloplasty using a transperitoneal route, while, in expert hands, both approaches are feasible and the choice depends on personal preference.

\section{Conclusion}

RALP represents a viable and innovative alternative to conventional LP, with comparable success and complication rates both in adult and in paediatric fields. The robotic approach seems to add further technical advantages when compared to conventional LP but sustains higher costs.

Currently, the choice to adopt one or the other minimally invasive approach depends on the surgeon's preference or experience, and on institutional availability.

Although the number of studies in this field has increased, further randomised controlled trials should be undertaken to draw stronger conclusions.

\section{Disclosure}

The authors report no conflicts of interest for this work.

\section{References}

1. Paraboschi I, Mantica G, Dalton NR, Turner C, Garriboli M. Urinary biomarkers in pelvic-ureteric junction obstruction: a systematic review. Translational Andrology Urology. 2020;9(2):722-742. doi:10.21037/tau.2020.01.01

2. Kausik S, Segura JW. Surgical management of ureteropelvic junction obstruction in adults. Int Braz j Urol. 2003;29(1):3-10. doi:10.1590/ S1677-55382003000100002

3. Eden CG. Minimally invasive treatment of ureteropelvic junction obstruction: a critical analysis of results. Eur Urol. 2007;52 (4):983-989.

4. Schuessler WW, Grune MT, Tecuanhuey LV, Preminger GM. Laparoscopic dismembered pyeloplasty. J Urol. 1993;150(6):1795-1799.

5. Autorino R, Eden C, El-Ghoneimi A, et al. Robot-assisted and laparoscopic repair of ureteropelvic junction obstruction: a systematic review and meta-analysis. Eur Urol. 2014;65(2):430-452.

6. Gettman MT, Neururer R, Bartsch G, Peschel R. Anderson-Hynes dismembered pyeloplasty performed using the da Vinci robotic system. Urology. 2002;60(3):509-513.

7. Bergersen A, Thomas R, Lee BR. Robotic Pyeloplasty. J Endourol. 2018;32(S1):S68-S72.

8. Moore RG, Averch TD, Schulam PG, Adams JB. Laparoscopic pyeloplasty: experience with the initial 30 cases. J Urol. 1997;157 (2):459-462.

9. Bachmann A, Ruszat R, Forster T, et al. Retroperitoneoscopic pyeloplasty for ureteropelvic junction obstruction (UPJO): solving the technical difficulties. Eur Urol. 2006;49(2):264-272. doi:10.1016/j. eururo.2005.12.036

10. Pelit ES, Ciftci H, Kati B, et al. Mini-laparoscopic pyeloplasty in adults: functional and cosmetic results. Urol J. 2018;15(6):339-343.
11. Rane A, Rao P, Rao P. Single-port-access nephrectomy and other laparoscopic urologic procedures using a novel laparoscopic port (R-port). Urology. 2008;72(2):260-263. doi:10.1016/j.urology.2008.01.078

12. Han HH, Ham WS, Kim JH, et al. Transmesocolic approach for left side laparoscopic pyeloplasty: comparison with laterocolic approach in the initial learning period. Yonsei Med J. 2013;54(1):197-203. doi:10.3349/ymj.2013.54.1.197

13. Peters CA, Schlussel RN, Retik AB. Pediatric laparoscopic dismembered pyeloplasty. J Urol. 1995;153(6):1962-1965. doi:10.1016/ S0022-5347(01)67378-6

14. Nakada SY, McDougall EM, Clayman RV. Laparoscopic pyeloplasty for secondary ureteropelvic junction obstruction: preliminary experience. Urology. 1995;46(2):257-260. doi:10.1016/S0090-4295(99)80205-2

15. Hammady A, Abdelgalil W, Rashed E, Elbadry MS. Upper urinary tract retroperitoneoscopic surgery under epidural anesthesia: shifting towards outpatient treatment. Scand J Urol. 2015;49(2):181-184. doi:10.3109/21681805.2014.971426

16. Srinivasan AK, Shrivastava D, Kurzweil RE, Weiss DA, Long CJ, Shukla AR. Port Site Local Anesthetic Infiltration Vs Single-dose Intrathecal Opioid Injection to Control Perioperative Pain in Children Undergoing Minimal Invasive Surgery: A Comparative Analysis. Urology. 2016;97:179-183. doi:10.1016/j.urology.2016.04.064

17. Cestari A, Buffi NM, Lista G, et al. Retroperitoneal and transperitoneal robot-assisted pyeloplasty in adults: techniques and results. Eur Urol. 2010;58(5):711-718. doi:10.1016/j.eururo.2010.07.020

18. Heo JE, Kang SK, Koh DH, et al. Pure single-site robot-assisted pyeloplasty with the da Vinci SP surgical system: initial experience. Invest Clin Urol. 2019;60(4):326-330. doi:10.4111/icu.2019.60.4.326

19. Gaboardi F, Smelzo S, Mantica G, et al. Minimally-invasive robotic pyeloplasty: the 'window technique'. Cent European J Urol. 2019;72 (3):331.

20. Gaboardi F, Mantica G, Smelzo S, et al. Robotic-assisted laparoscopic pyeloplasty with the use of the Contour ${ }^{\mathrm{TM}}$ stent: description of the technique and analysis of outcomes after the first 30 cases. Cent European J Urol. 2019;72(1):51-53.

21. Uberoi J, Disick GI, Munver R. Minimally invasive surgical management of pelvic-ureteric junction obstruction: update on the current status of robotic-assisted pyeloplasty. BJU Int. 2009;104(11):1722-1729.

22. Citgez S, Demirdag C, Ozman O, Ozden SB, Derekoylu E, Onal B. Comparison of a Modified Antegrade and Retrograde Ureteral Double-J Stenting Techniques during Laparoscopic and Robotic Pyeloplasty. Urol Int. 2020;104(1-2):87-93.

23. Arumainayagam N, Minervini A, Davenport K, et al. Antegrade versus retrograde stenting in laparoscopic pyeloplasty. J Endourol. 2008;22(4):671-674.

24. Abbas TO, Ali M, Moog R. "Double-Lumen Valve-Controlled IntraOperative Pyeloplasty Stent (VIPs)": A New Technology for PostPyeloplasty Stenting - Proof of Concept Study in a Preclinical Large Animal Model. Res Rep Urol. 2020;12:61-74.

25. Bilen CY, Bayazit Y, Güdeloğlu A, Abat D, Inci K, Doran S. Laparoscopic pyeloplasty in adults: stented versus stentless. $J$ Endourol. 2011;25(4):645-650.

26. Howe A, Kozel Z, Palmer L. Robotic surgery in pediatric urology. Asian J Urol. 2017;4(1):55-67.

27. Esposito C, Masieri L, Castagnetti M, et al. Robot-assisted vs laparoscopic pyeloplasty in children with uretero-pelvic junction obstruction (UPJO): technical considerations and results. $J$ Pediatr Urol. 2019;15(6):667.e1-667.e8.

28. Hong P, Ding G, Zhu D, et al. Head-to-Head Comparison of Modified Laparoscopic Pyeloplasty and Robot-Assisted Pyeloplasty for Ureteropelvic Junction Obstruction in China. Urol Int. 2018;101 (3):337-344.

29. Light A, Karthikeyan S, Maruthan S, Elhage O, Danuser H, Dasgupta P. Peri-operative outcomes and complications after laparoscopic vs robot-assisted dismembered pyeloplasty: a systematic review and meta-analysis. BJU Int. 2018;122(2):181-194. 
30. Uhlig A, Uhlig J, Trojan L, Hinterthaner M. Von HammersteinEquord A and Strauss A. Surgical approaches for treatment of ureteropelvic junction obstruction - a systematic review and network metaanalysis. BMC Urol. 2019;19:112.

31. Khoder WY, Waidelich R, Ghamdi AMA, Schulz T, Becker A, Stief CG. A prospective randomised comparison between the transperitoneal and retroperitoneoscopic approaches for robotic-assisted pyeloplasty in a single surgeon, single centre study. J Robot Surg. 2018;12(1):131-137.

32. Amón Sesmero JH, Delgado MC, de la Cruz Martín B, Serrano MR, Mainez Rodríguez JA, Tapia Herrero AM. Laparoscopic Pyeloplasty: always Dismembered? J Endourol. 2016;30(7):778-782.

33. Sorensen MD, Delostrinos C, Johnson MH, Grady RW, Lendvay TS. Comparison of the learning curve and outcomes of robotic assisted pediatric pyeloplasty. $J$ Urol. 2011;185(6 Suppl):2517-2522.

34. Andolfi C, Adamic B, Oommen J, Gundeti MS. Robot-assisted laparoscopic pyeloplasty in infants and children: is it superior to conventional laparoscopy? World J Urol. 2020;38(8):1827-1833.

35. Aksenov LI, Granberg CF, Gargollo PC. A Systematic Review of Complications of Minimally Invasive Surgery in the Pediatric Urological Literature. J Urol. 2020;203(5):1010-1016.

36. Hamedanchi S, Sedokani A. Color Doppler Ultrasonography in Evaluating the Outcomes of Pyeloplasty in Ureteropelvic Junction Obstruction. Res Rep Urol. 2020;12:53-59.

37. Shahnawaz R, et al. Comparison of open, laparoscopic and robotassisted pyeloplasty for pelviureteric junction obstruction in adult patients. J Robot Surg. 2020;14:325-329.

38. Rassweiler JJ, Teber D, Frede T. Complications of laparoscopic pyeloplasty. World J Urol. 2008;26:539-547.

39. Hopf HL, Bahler CD, Sundaram CP. Long-term Outcomes of Robot-assisted Laparoscopic Pyeloplasty for Ureteropelvic Junction Obstruction. Urology. 2016;90:106-110.

40. Taktak S, Llewellyn O, Aboelsoud M, Hajibandeh S, Hajibandeh S. Robot-assisted laparoscopic pyeloplasty versus laparoscopic pyeloplasty for pelvi-ureteric junction obstruction in the paediatric population: a systematic review and meta-analysis. Ther Adv Urol. 2019;11:1756287219835704.

41. Uhlig A, Uhlig J, Trojan L, Hinterthaner M. Von HammersteinEquord A and Strauss A. Surgical approaches for treatment of ureteropelvic junction obstruction - a systematic review and network metaanalysis. BMC Urol. 2019;19:112.

42. Zhang X, Li HZ, Ma X, et al. Retrospective comparison of retroperitoneal laparoscopic versus open dismembered pyeloplasty for ureteropelvic junction obstruction. J Urol. 2006;176:1077-1080.

43. Rasool S, Singh M, Jain S, et al. Comparison of open, laparoscopic and robot-assisted pyeloplasty for pelviureteric junction obstruction in adult patients. $J$ Robot Surg. 2020;14(2):325-329.

44. Mendrek M, Vögeli TA, Bach C. Recent advances in urologic surgical techniques for pyeloplasty. F1000Res. 2019;85.
45. Zhang Y, Ouyang W, Xu H, et al. Secondary Management for Recurrent Ureteropelvic Junction Obstruction after Pyeloplasty: A Comparison of Re-Do Robot-Assisted Laparoscopic Pyeloplasty and Conventional Laparoscopic Pyeloplasty. Urol Int. 2019;103 (4):466-472.

46. Asensio M, Gander R, Royo GF, Lloret J. Failed pyeloplasty in children: is robot-assisted laparoscopic reoperative repair feasible? J Pediatr Urol. 2015;11(2):69.e1-69.e696.

47. Blanc T, Koulouris E, Botto N, Paye-Jaouen A, El-Ghoneimi A. Laparoscopic pyeloplasty in children with horseshoe kidney. $J$ Urol. 2014;191(4):1097-1103.

48. Esposito C, Masieri L, Blanc T, Manzoni G, Silay S, Escolino M. Robot-assisted laparoscopic pyeloplasty (RALP) in children with horseshoe kidneys: results of a multicentric study. World $J$ Urol. 2019;37(10):2257-2263.

49. Yu H, Hevelone ND, Lipsitz SR, Kowalczyk KJ, Hu JC. Use, costs and comparative effectiveness of robotic assisted, laparoscopic and open urological surgery. J Urol. 2012;187(4):1392-1398.

50. Link RE, Bhayani SB, Kavoussi LR. A prospective comparison of robotic and laparoscopic pyeloplasty. Ann Surg. 2006;243:486-491.

51. Junejo NN, Alotaibi A, Alshahrani SM, et al. The learning curve for robotic-assisted pyeloplasty in children: our initial experience from a single center. Urol Ann. 2020;12(1):19-24.

52. Pio L, Musleh L, Paraboschi I, et al. Learning curve for robotic surgery in children: a systematic review of outcomes and fellowship programs. J Robot Surg. 2020;14(4):531-541.

53. Chammas MF, Mitre AI, Arap MA, Hubert N, Hubert J. Learning robotic pyeloplasty without simulators: an assessment of the learning curve in the early robotic era. Clinics. 2019;74:e777.

54. Kassite I, Braik K, Villemagne T, Lardy H, Binet A. The learning curve of robot-assisted laparoscopic pyeloplasty in children: a multi-outcome approach. J Pediatr Urol. 2018;14(6):570.e1-570.e10.

55. Dothan D, Raisin G, Jaber J, Kocherov S, Chertin B. Learning curve of robotic-assisted laparoscopic pyeloplasty (RALP) in children: how to reach a level of excellence? [published online ahead of print, 2020 Apr 24]. J Robot Surg. 2020;10.

56. Bowen DK, Lindgren BW, Cheng EY, Gong EM. Can proctoring affect the learning curve of robotic-assisted laparoscopic pyeloplasty? Experience at a high-volume pediatric robotic surgery center. $J$ Robot Surg. 2017;11(1):63-67.

57. Panek W, Szmer J, Kuijper CF, Chrzan R. Learning curve or experience-related outcome: what really matters in paediatric laparoscopic pyeloplasty. Wideochir Inne Tech Maloinwazyjne. 2020;15 (2):377-381.

58. Zhu H, Shen C, Li X, et al. Laparoscopic pyeloplasty: a comparison between the transperitoneal and retroperitoneal approach during the learning curve. Urol Int. 2013;90(2):130-135.
Research and Reports in Urology

\section{Publish your work in this journal}

Research and Reports in Urology is an international, peer-reviewed, open access journal publishing original research, reports, editorials, reviews and commentaries on all aspects of adult and pediatric urology in the clinic and laboratory including the following topics: Pathology, pathophysiology of urological disease; Investigation and treatment of urological disease; Pharmacology of drugs used for the treatment of urological disease. The manuscript management system is completely online and includes a very quick and fair peer-review system, which is all easy to use. Visit http://www.dovepress.com/ testimonials.php to read real quotes from published authors. 